\title{
DNA Double-strand Break Signaling Is a Therapeutic Target in Head and Neck Cancer
}

\author{
JIANCHUN WU ${ }^{1}$, KATE JILLIAN GALVAN ${ }^{2}$, RYAN D. BOGARD ${ }^{1}$, \\ CARYN E. PETERSON ${ }^{3}$, ARDAMAN SHERGILL ${ }^{4}$ and DAVID L. CROWE ${ }^{1}$ \\ ${ }^{1}$ University of Illinois Cancer Center, Chicago, IL, U.S.A.; \\ ${ }^{2}$ University of Illinois College of Medicine, Chicago, IL, U.S.A.; \\ ${ }^{3}$ University of Illinois School of Public Health, Chicago, IL, U.S.A.; \\ ${ }^{4}$ Section of Hematology/Oncology, Department of Medicine, \\ University of Chicago Pritzker School of Medicine, Chicago, IL, U.S.A.
}

\begin{abstract}
Background: Head and neck cancer (HNC) is common worldwide. Given poor outcomes for patients with $H N C$, research into targeted therapies is needed. Ataxia telangiectasia mutated (ATM) is a DNA damage kinase which is activated by double-strand DNA breaks. We tested the effects of a novel ATM inhibitor on HNC cell lines and xenografts. Materials and Methods: p53-Binding protein 1 and phosphorylated ATM were localized in cultured cells by immunofluorescence microscopy. Protein expression was determined by western blot. Tumor xenografts were established by injecting HNC lines into immunocompromised mice. Tumor sections were characterized by immunohistochemistry. Apoptotic cells were determined by terminal transferasemediated dUTP nick-end labeling assay. Results: ATM inhibition increased double-strand DNA breaks at replication foci in HNC cell lines. ATM inhibition affected cell-cycle regulatory protein expression, blocked cell-cycle progression at the $G_{2} / M$ phase and resulted in apoptosis. Conclusion: ATM inhibition may be therapeutically useful in treating $H N C$.
\end{abstract}

Head and neck cancer (HNC) is common worldwide, with more than 600,000 cases each year (1). HNC is associated with tobacco and alcohol use, and in recent decades human papillomavirus (HPV) infection has been associated with a subset of cancer of the oropharynx (2). The majority of

This article is freely accessible online.

Correspondence to: David L. Crowe, $801 \mathrm{~S}$. Paulina Street, Room 525, Chicago, IL 60612, USA. E-mail: dlcrowe@uic.edu and Ardaman Shergill, 924 E. 57th Street, Chicago, IL 60637, U.S.A. E-mail: ashergill@uchicago.edu

Key Words: Ataxia telangiectasia mutated, human papillomavirus, targeted therapy, biomarker. patients with head and neck squamous cell carcinoma presents with advanced tumors and lymph node metastasis, and recurrence after treatment is a frequent clinical problem (2). Standard treatment for advanced tumors consists of concurrent chemoradiation followed by surgery.

A few targeted therapies have been approved for treatment of HNC. The anti-epidermal growth factor receptor antibody cetuximab was approved for recurrent and metastatic HNC $(3,4)$. More recently, immune checkpoint inhibitors such as the programmed cell death protein 1 antibodies nivolumab and pembrolizumab were approved for patients with recurrent or metastatic disease previously treated with platinum chemotherapy $(2,5)$. Given poor clinical outcomes for many patients with $\mathrm{HNC}$, additional research into targeted therapies is needed.

Ataxia telangiectasia mutated (ATM) is a DNA damage kinase which is activated by double-strand DNA breaks, and phosphorylates numerous downstream protein targets (6). When activated, ATM normally arrests the cell cycle to allow DNA repair to occur. Activated ATM is associated with double-strand breaks during DNA synthesis, which may be the result of replication stress. ATM inhibitors may kill cancer cells due to the persistence of unrepaired doublestrand breaks leading to apoptosis.

ATM inhibitors have largely been unsuccessful in the cancer clinic. AZD1390 is a first-in-class orally available ATM inhibitor with greater than $10^{4}$-fold selectivity over other phosphatidylinositol 3'-kinases (7). We tested the effects of novel ATM inhibitor AZD1390 on HNC cell lines and xenografts.

\section{Materials and Methods}

Cell culture. Human HPV- SCC lines SCC9, SCC15, SCC25 and SCC71, and HPV ${ }^{+}$lines SCC152 and SCC154 were purchased from the American Type Culture Collection (Manassas, VA, USA); 
SCC90 and SCC104 were purchased from MilliporeSigma (Burlington, MA, USA). Cells were cultured in Dulbecco's modified Eagle's medium with $10 \%$ fetal bovine serum, $40 \mu \mathrm{g} / \mathrm{ml}$ gentamicin at $37^{\circ} \mathrm{C}$ in a humidified atmosphere of $5 \% \mathrm{CO}_{2}$. All cell lines were negative for mycoplasma. Triplicate cultures were treated with $0.2-$ $5 \mu$ M ATM inhibitor AZD1390 (Selleck Chemicals, Houston, TX, USA) for 1-5 days. Cell death was monitored by trypan blue exclusion analysis. The positive cell fraction was determined using a quantitative digital pathology image analysis system (Vectra 3; Akoya Biosciences, Marlborough, MA, USA).

Antibodies. The following antibodies were used in this study: ATM (AB201022), phospho-checkpoint kinase 2 (pCHK2T68) (AB85743), human papillomavirus (HPV) virion (HPV L1) (AB25275), cyclindependent kinase inhibitor 2A (p16 INK4A) (AB54210), p-histone H3 (AB47297), anti-IgG/Alexfluor 488 (AB650077), and antiIgG/Alexafluor 555 (AB150074) from Abcam (Waltham, MA, USA); checkpoint kinase 2 (CHK2) (611570), cyclin-dependent kinase 1 (CDK1) (C12720), CDK2 (C18520), cyclin D1 (C20320) and p53 (554147) from BD Biosciences (Franklin Lakes, NJ, USA); $\beta$-actin (4970S) from Cell Signaling (Danvers, MA, USA); p53 binding protein 1 (53BP1) (NB100-304) from Novus (Centennial, CO, USA);

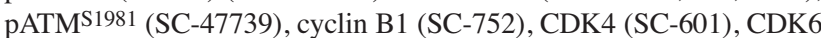
(SC-177), proliferating cell nuclear antigen (PCNA) (SC-7907) from Santa Cruz Biotechnology (Dallas, TX, USA) and keratin 10 antibody (K10) (C-7284) from Sigma (St. Louis, MO, USA).

Mouse procedures. Mouse procedures were approved by the Institutional Animal Care Committee (19-027) and performed in accordance with ARRIVE guidelines (8). Immunocompromised NU/J mice were purchased from The Jackson Laboratory (Bar Harbor, ME, USA; $n=10$ for each cell line). This sample size would allow detection of greater than $25 \%$ reduction in tumor volume due to treatment with alpha error $=0.05$ and power $=0.8$. Two-month-old male and female mice were subcutaneously injected with $10^{6}$ cells from each line suspended in $0.1 \mathrm{ml}$ Matrigel. Mice with $100 \mathrm{~mm}^{3}$ tumors were randomly assigned to $50 \mathrm{mg} / \mathrm{kg}$ AZD1390 or vehicle-treated groups AZD1390 or vehicle was administered by oral gavage. Mice were dosed once daily for 5 days. Tumor volume was recorded daily for each animal. Mice underwent complete necropsy after day 5 . Tumors were dissected and fixed in $4 \%$ buffered formaldehyde. Researchers were blinded to identities of control and experimental samples.

Histopathology, immunofluorescence, and immunohistochemistry. In cell culture experiments, cells were treated with $0.2 \mu \mathrm{M}$ AZD1390 or vehicle for 16 hours and fixed in $2 \%$ formaldehyde for 10 minutes, permeabilized with $70 \%$ ethanol for 10 minutes, washed in phosphate-buffered saline (PBS), and incubated with 1:100 dilution of antibodies to 53BP1, pATM, and PCNA. After washing, cells were incubated with anti-IgG secondary antibodies conjugated to AlexaFluor 488 or AlexaFluor 555. After washing, slides were counterstained with 4',6-diamidino-2-phenylindole (DAPI) and coverslipped with anti-fade mounting medium. For histopathology experiments, formalin-fixed tumors were dehydrated in ethanol, cleared in xylene, and embedded in paraffin. Tumor sections were deparaffinized and stained with hematoxylin and eosin. For immunofluorescence experiments, tumor sections were rehydrated in PBS ( $\mathrm{pH} 7.4$ ), blocked with $10 \%$ normal serum, and incubated with HPV L1 or keratin 10 antibodies overnight at room temperature. After washing, sections were incubated with anti-IgG secondary antibodies conjugated to AlexaFluor 488 or AlexaFluor 555. After washing, slides were counterstained with DAPI and coverslipped with anti-fade mounting medium. Sections were visualized using fluorescence microscopy (Zeiss LSM 710 META; Zeiss, White Plains, NY, USA). For immunohistochemical analysis, sections were rehydrated in PBS and blocked using 10\% normal serum and incubated with 1:50 dilution of pATM, PCNA, p16 INK4A, or pCHK2 antibodies overnight at room temperature. After washing, sections were incubated with biotinylated secondary antibody at room temperature for $10 \mathrm{~min}$. After additional washing, sections were incubated with streptavidin-conjugated horseradish peroxidase for $10 \mathrm{~min}$ at room temperature. Antigen-antibody complexes were detected by incubation with peroxide substrate solution containing aminoethylcarbazole chromogen. The positive cell fraction was determined using a quantitative digital pathology image analysis system (Vectra 3; Akoya Biosciences).

Transmission electron microscopy. To determine if tumor xenografts produce HPV virions, tumor xenografts were fixed in phosphatebuffered $2 \%$ glutaraldehyde, postfixed in phosphate-buffered $1 \%$ osmium tetroxide, dehydrated in acetone series, infiltrated in propylene oxide/resin, and embedded in Epon resin. Sections of $0.1 \mathrm{~mm}$ were stained with uranyl acetate and lead citrate and imaged using a JEOL JEM-1220 electron microscope (JEOL, Peabody, MA, USA)

Cell death analysis by terminal transferase-mediated dUTP nickend labeling (TUNEL) assay. Tumor sections or human SCC cells treated with DMSO or $0.2 \mu \mathrm{M}$ AZD1390 for 16 hours were fixed, permeabilized, and incubated with terminal deoxynucleotidyl transferase and dUTP-fluorescein for $1 \mathrm{~h}$ at $37^{\circ} \mathrm{C}$ according to manufacturer's recommendations (Roche Applied Sciences, Indianapolis, IN, USA). After washing, apoptotic cells were visualized by fluorescence microscopy. The fluorescent cell fraction was determined using a quantitative digital pathology image analysis system (Vectra 3; Akoya Biosciences).

Western blot. Protein was extracted from human SCC lines treated with DMSO or $0.2 \mu \mathrm{M}$ AZD1390 for 16 hours in $1 \times$ Laemmli buffer $(0.1$ $\mathrm{M}$ Tris- $\mathrm{HCl}, \mathrm{pH} 6.8,2 \%$ sodium dodecyl sulfate, $0.1 \mathrm{M}$ dithiothreitol, $10 \%$ glycerol, $0.0025 \%$ bromophenol blue). $75 \mu$ g total cellular protein was separated by sodium dodecyl sulfate-polyacrylamide gel electrophoresis. Proteins were electroblotted to polyvinylidene difluoride membranes. Blots were incubated with antibodies to pATMSer1981, ATM, CHK2, p53, cyclin B, cyclin D, CDK1, CDK2, $\mathrm{CDK} 4, \mathrm{CDK} 6$, p-histone $\mathrm{H} 3^{\mathrm{S} 10}$, or $\beta$-actin for 16 hours at $4^{\circ} \mathrm{C}$. After washing, blots were incubated for 30 minutes at room temperature with anti-IgG secondary antibody conjugated to horseradish peroxidase. Bands were visualized by the enhanced chemiluminescence method, normalized to $\beta$-actin expression, and quantitated by image analysis software (Silk Scientific, Orem, UT, USA).

Fluorescence-activated cell sorting. Human SCC lines treated with DMSO or $0.2 \mu \mathrm{M}$ AZD1390 for 16 hours were dissociated by trypsinization, washed in PBS, fixed in $70 \%$ ethanol, stained with propidium iodide, washed in PBS, and subjected to cell-cycle analysis by fluorescence-activated cell sorting.

Statistical analysis. Parametric data were analyzed by unpaired twosided $t$-test. Non-parametric data were analyzed by Fisher exact test. 

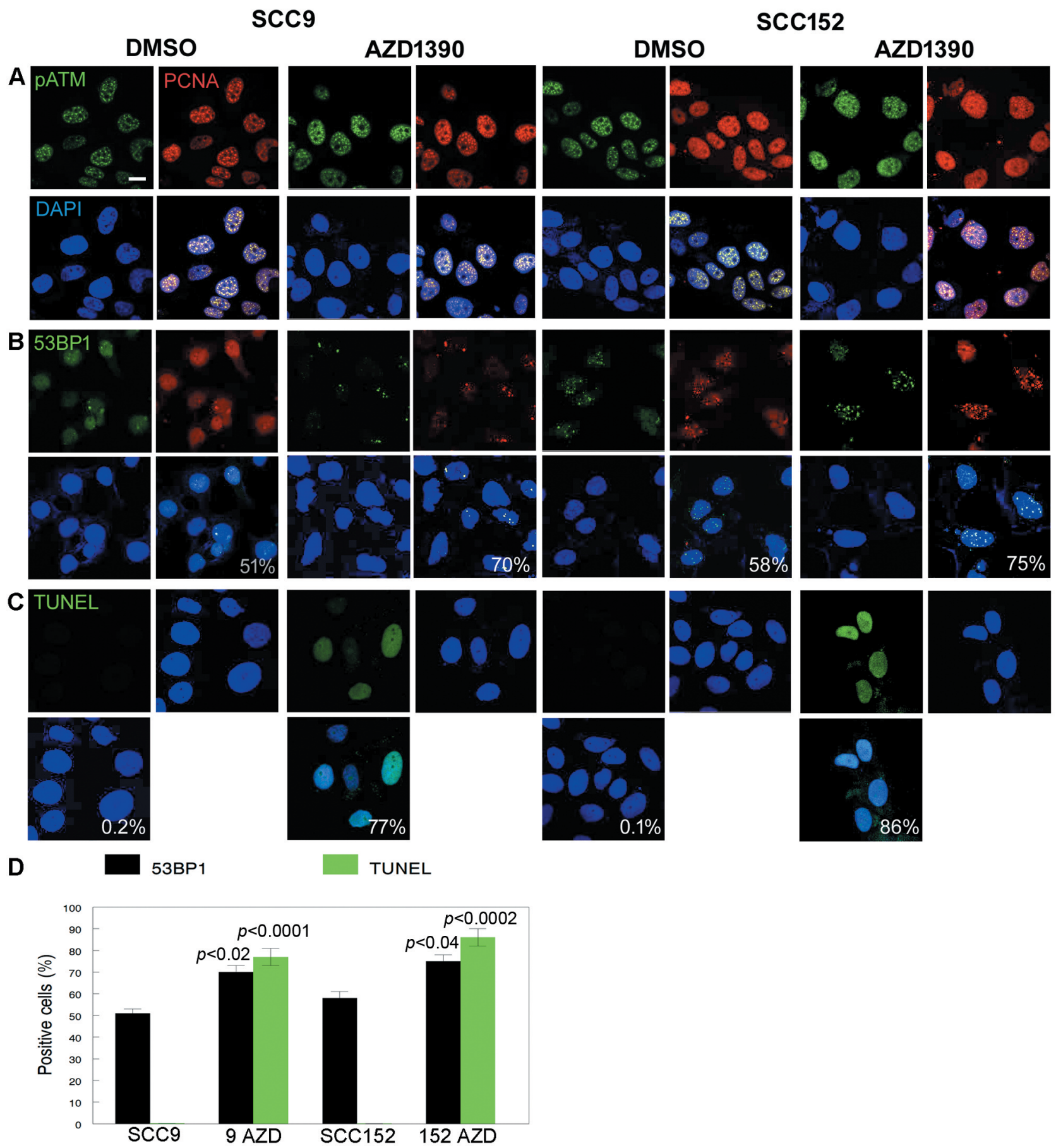

Figure 1. Inhibition of ataxia telangiectasia mutated (ATM) increases double-strand DNA breaks at replication foci and head and neck cancer cell death in vitro. A: phospho ( $p$ )ATM expression at proliferating cell nuclear antigen (PCNA+) DNA replication foci in dimethyl sulfoxide (DMSO)treated and in AZD1390-treated SCC9 and SCC152 cells as shown by immunofluorescence microscopy. B: p53-binding protein 1 (53BP1) expression at PCNA+ DNA replication foci in DMSO-treated and in AZD1390-treated SCC9 and SCC152 cells as shown by immunofluorescence microscopy. Programmed cell death in DMSO-treated and in AZD1390-treated SCC9 and SCC152 cells as shown by terminal transferase-mediated dUTP nickend labeling (TUNEL) analysis. Nuclei were counterstained with 4',6-diamidino-2-phenylindole (DAPI). Scale bar=10 $\mu \mathrm{m}$. C: Quantitation of $53 \mathrm{BP}^{+}$and TUNEL+ cells in SCC9 and SCC152 lines treated with DMSO or AZD1390. Error bars indicate SEM. Experiments were performed three times with similar results. 


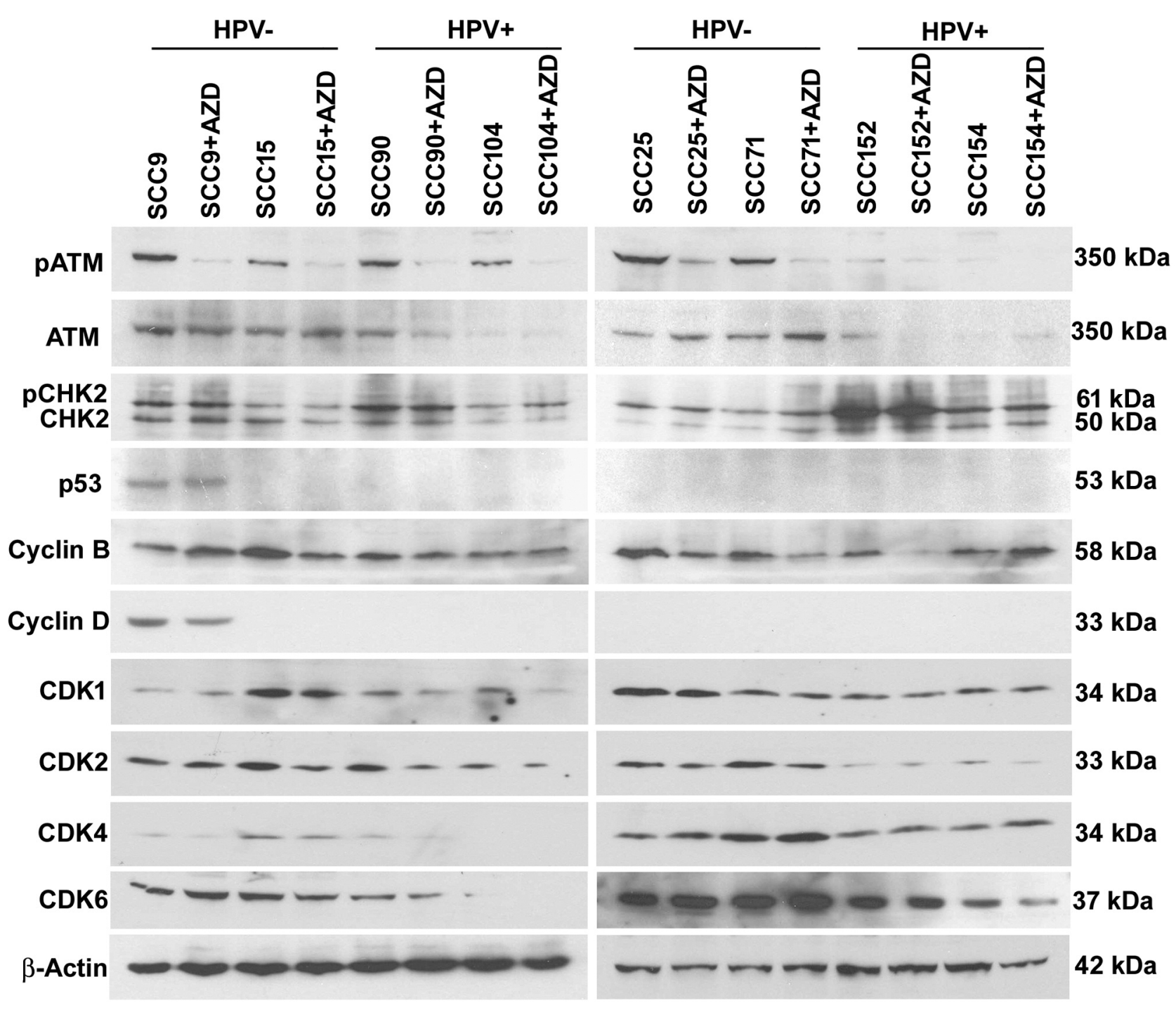

Figure 2. Inhibition of ataxia telangiectasia mutated (ATM) reduces expression of cell cycle-regulatory proteins in head and neck cancer (HNC) cell lines. ATM, phospho (p)-ATM, checkpoint kinase 2 (CHK2), pCHK2, p53, cyclin B, cyclin D, cyclin dependent kinase 1 (CDK1), CDK2, CDK4, and CDK6 expression in eight HNC cell lines treated with dimethyl sulfoxide (DMSO) or AZD1390 is shown by western blot. $\beta$-Actin expression was used to control for protein loading in each lane. Experiments were performed three times with similar results.

\section{Results}

A novel ATM inhibitor increased double-strand DNA breaks and impaired survival of HNC cell lines. Previous ATM inhibitors have been largely unsuccessful in the cancer clinic. To determine if use of a novel ATM inhibitor AZD1390 results in increased double-strand breaks in HNC cell lines, we examined pATM and 53BP1 expression at $\mathrm{PCNA}^{+}$ replication foci in $\mathrm{HPV}^{-} \mathrm{SCC} 9$ and $\mathrm{HPV}^{+} \mathrm{SCC} 152$ cells treated with DMSO or $0.2 \mu \mathrm{M}$ AZD1390 for 16 hours. pATM colocalized at $\mathrm{PCNA}^{+}$DNA replication foci in DMSO and AZD1390-treated $\mathrm{HPV}^{+}$and $\mathrm{HPV}^{-}$cells (98\%; Figure
1A). ATM inhibition increased $53 \mathrm{BP} 1^{+}$co-localization at DNA replication foci in both $\mathrm{HPV}^{-}(70 \%$ vs. $51 \% ; p<0.02)$ and $\mathrm{HPV}^{+}(75 \%$ vs. $58 \%$; $p<0.04) \mathrm{HNC}$ cell lines (Figure $1 \mathrm{~B}$ and $\mathrm{C})$. ATM inhibition increased the $\mathrm{TUNEL}^{+}$cell fraction in $\mathrm{HPV}^{-}(77 \%$ vs. $0.2 \% ; p<0.0001)$ and $\mathrm{HPV}^{+}(86 \%$ vs. $0.1 \% ; p<0.00002) \mathrm{HNC}$ cell lines (Figure 1D). Similar results were observed in additional $\mathrm{HPV}^{-}$and $\mathrm{HPV}^{+} \mathrm{HNC}^{-}$ cell lines (data not shown). These results indicate that ATM inhibition results in increased double-strand breaks in $\mathrm{HPV}^{-}$ and $\mathrm{HPV}^{+} \mathrm{HNC}$ cell lines. Increased double-strand DNA breaks correlated with programmed cell death in $\mathrm{HPV}^{-}$and $\mathrm{HPV}^{+} \mathrm{HNC}$ lines. 

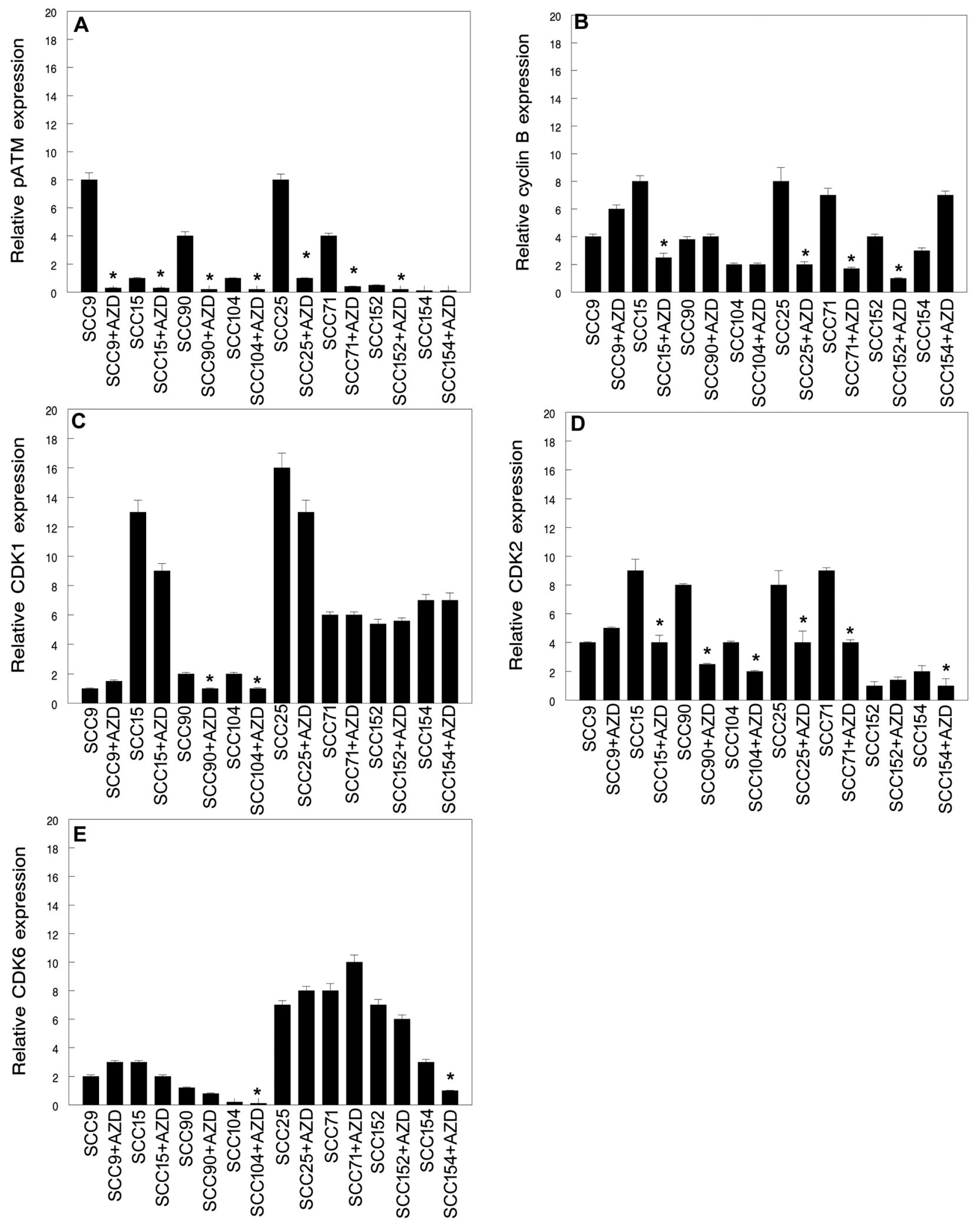

Figure 3. Quantitation of phospho-ataxia telangiectasia mutated (ATM) (A), cyclin B (B), cyclin-dependent kinase 1 (CDK1) (C), CDK2 (D), and CDK6 (E) protein expression in indicated SCC cell lines treated with vehicle or AZD1390. Error bars indicate the standard error of the mean. Asterisks indicate statistically significant differences from control cells. 
ATM inhibition regulates expression of cell-cycle proteins in $H N C$ cell lines. To determine if ATM inhibition affected expression of cell-cycle regulatory proteins in HNC, we examined expression of these proteins by western blot. pATM expression was reduced 2-to 8-fold by AZD1390 treatment of $\mathrm{HPV}^{-} \mathrm{SCC} 9, \mathrm{SCC} 15, \mathrm{SCC} 25$ and SCC71, and $\mathrm{HPV}^{+} \mathrm{SCC} 90$, SCC104 and SCC152 cell lines $(p<0.05$; Figure 2 and Figure 3). $\mathrm{pCHK}_{2}$ expression was detected in $\mathrm{HPV}^{-}$and $\mathrm{HPV}^{+}$cell lines and was unaffected by AZD1390 treatment, likely due to phosphorylation by other DNA-damage kinases (see Discussion). Expression of $\mathrm{G}_{2} / \mathrm{M}$-phase cyclin $\mathrm{B}$ was inhibited 3-fold in $\mathrm{HPV}^{-} \mathrm{SCC} 15$ and 4-fold in $\mathrm{HPV}^{-} \mathrm{SCC} 25$ and $\mathrm{SCC}_{1} 1$ and $\mathrm{HPV}^{+} \mathrm{SCC} 152$ cell lines by AZD1390 treatment $\left(p<0.01\right.$; Figure 2 and Figure 3). Expression of the $\mathrm{G}_{2} / \mathrm{M}$ phase CDK1 was inhibited by 2 -fold in $\mathrm{HPV}^{+} \mathrm{SCC} 90$ and SCC104 cell lines by AZD1390 treatment $(p<0.05$; Figure 2 and Figure 3). Expression of S-phase CDK2 expression was inhibited by 2 -fold in $\mathrm{HPV}^{-} \mathrm{SCC} 15, \mathrm{SCC} 25$ and $\mathrm{SCC} 71$, and $\mathrm{HPV}^{+} \mathrm{SCC} 104, \mathrm{SCC} 154$ cells, and 3 -fold in $\mathrm{HPV}^{+} \mathrm{SCC} 0$ cells by AZD1390 treatment ( $p<0.02$; Figure 2 and Figure 3 ). Expression of $\mathrm{G}_{1}$-phase CDK6 was inhibited by 2 -fold in $\mathrm{HPV}^{+}$SCC104 and SCC154 cell lines by AZD1390 treatment $\left(p<0.05\right.$; Figure 2 and Figure 3). Expression of $\mathrm{G}_{1}$-phase CDK4 was not significantly affected by AZD1390 treatment. Expression of p53 and $\mathrm{G}_{1}$-phase cyclin D1 was detected only in $\mathrm{HPV}^{-}$SCC9 cells and was not affected by AZD1390 treatment. p53 is expressed at low levels in most cells due to MDM2 proto-oncogene ubiquitin ligase and loss of heterozygosity in cancer cells, although some cancerassociated p53 mutants exhibit increased protein stability (9). Cyclin D1 also is overexpressed in some HNCs (10). These results indicate that ATM inhibition regulates expression of $\mathrm{S}$ and $\mathrm{G}_{2} / \mathrm{M}$-phase cell cycle-related proteins in HNC cell lines.

ATM inhibition regulates cell-cycle progression in HNC cell lines. To determine if reduced expression of $\mathrm{G}_{2} / \mathrm{M}$-phase proteins affects cell-cycle progression, we profiled vehicle and AZD1390-treated HNC cell lines by fluorescenceactivated cell sorting. AZD1390 treatment reduced $\mathrm{G}_{2} / \mathrm{M}$ phase $\mathrm{HPV}^{-}$SCC9 (4.2\% vs. 18.3\%; $p<0.007$; Figure 4A) and $\mathrm{HPV}^{+} \mathrm{SCC} 152(6.7 \%$ vs. $16.8 \% ; p<0.01$; Figure $4 \mathrm{~B}$ and C) cell fractions. Similar results were observed in additional $\mathrm{HPV}^{-}$and $\mathrm{HPV}^{+}$cell lines (data not shown). Expression of the S-phase protein phospho-histone $\mathrm{H} 3$ was increased 9-fold by AZD1390 treatment (Figure 4C), indicating cell-cycle block at the $\mathrm{G}_{2} / \mathrm{M}$-phase checkpoint. These results indicate ATM inhibition blocks cell-cycle progression at $\mathrm{G}_{2} / \mathrm{M}$ phase in $\mathrm{HPV}^{-}$and $\mathrm{HPV}^{+} \mathrm{HNC}$ cell lines, likely due to accumulation of double-strand DNA breaks.

ATM inhibition induces cell death in HNC lines. To confirm if ATM inhibition induces cell death in $\mathrm{HPV}^{-}$and $\mathrm{HPV}^{+} \mathrm{HNC}$ cell lines, we performed in vitro time course and dose-response experiments using trypan blue exclusion analysis. AZD1390 treatment induced time- and dose-dependent cell death in $\mathrm{HPV}^{-} \mathrm{SCC} 9$ (Figure 5A) and $\mathrm{HPV}^{+} \mathrm{SCC} 152$ (Figure 5B) cell lines, with $5 \mu \mathrm{M}$ AZD1390 resulting in no viable cells by 4 days of treatment. Similar results were observed in additional $\mathrm{HPV}^{-}$and $\mathrm{HPV}^{+}$cell lines (data not shown). There were no statistically significant differences in cell death between $\mathrm{HPV}^{-}$ and $\mathrm{HPV}^{+}$cell lines. These results indicate that ATM inhibition induces cell death in $\mathrm{HPV}^{-}$and $\mathrm{HPV}^{+} \mathrm{HNC}$ cell lines in vitro.

ATM inhibition inhibits growth of HNC xenografts. To determine the effects of ATM inhibition on HNC growth in vivo, we transplanted $\mathrm{HPV}^{-}$and $\mathrm{HPV}^{+}$cancer cell lines subcutaneously in NU/J mice. $\mathrm{HPV}^{+}$xenografts expressed high levels of the HPV capsid protein L1 as shown by immunofluorescence microscopy which was not observed in $\mathrm{HPV}^{-}$transplanted tumors (Figure 6A and C). HPV virions were observed in xenografts derived from $\mathrm{HPV}^{+} \mathrm{HNC}$ cell lines as shown by transmission electron microscopy (Figure $6 \mathrm{~B}$ and $\mathrm{D})$. This is a novel result which has not been previously reported. We treated mice with transplanted tumors with vehicle or AZD1390. AZD1390 treatment inhibited tumor growth by $87 \%$ in $\mathrm{HPV}^{-} \mathrm{SCC} 9$ and $82 \%$ in $\mathrm{HPV}^{+}$ SCC152 transplanted mice $(p<0.0008$; Figure 6E). Similar results were observed in additional $\mathrm{HPV}^{-}$and $\mathrm{HPV}^{+}$cell lines (data not shown). These results indicate that AZD1390 inhibits growth of $\mathrm{HPV}^{-}$and $\mathrm{HPV}^{+} \mathrm{HNC}$ cell lines in vivo.

ATM inhibition inhibits proliferation and induces cell death in HNC xenografts. We examined AZD1390- and vehicletreated $\mathrm{HPV}^{-}$and $\mathrm{HPV}^{+}$transplanted $\mathrm{HNC}$ by histopathology, immunohistochemistry, and TUNEL analysis. Vehicle-treated mice bearing transplanted $\mathrm{HPV}^{-}$and $\mathrm{HPV}^{-}$ tumors were highly cellular and poorly differentiated (Figure 7A). Cells exhibited high nuclear/cytoplasmic ratio characteristic of proliferating basal cells observed in human HNC. AZD1390 treatment resulted in small hypocellular tumors with fragmented nuclei characteristic of programmed cell death (Figure 7A). $\mathrm{HPV}^{+}$tumors contained a high p16 ${ }^{\mathrm{INK} 4 \mathrm{~A}}$-positive cell fraction $(74 \%$ vs. $2 \% ; p<0.001)$ compared to $\mathrm{HPV}^{-}$tumors (Figure $7 \mathrm{~B}$ ), which is characteristic of human HNC. p16 $6^{\mathrm{INK} 4 \mathrm{~A}}$ expression was not detected in tumors from AZD1390-treated mice due to extensive cell death (Figure 7B). pATM was not detectable by immunohistochemistry in transplanted $\mathrm{HPV}^{-}$and $\mathrm{HPV}^{+}$ HNC (Figure 7C). However, expression of downstream target pCHK2 was increased in $\mathrm{HPV}^{+}$transplanted tumors (28\% vs. $1 \% ; p<0.003$ ) compared to $\mathrm{HPV}^{-}$tumors (Figure 7D). pCHK2 expression was not detected in tumors from AZD1390-treated mice due to extensive cell death (Figure 7D). The $\mathrm{PCNA}^{+}$proliferating cell fraction was high in both $\mathrm{HPV}^{-}$and $\mathrm{HPV}^{+}$transplanted tumors (59\% vs. 49\%; Figure 7E). PCNA expression was not detected in tumors from 

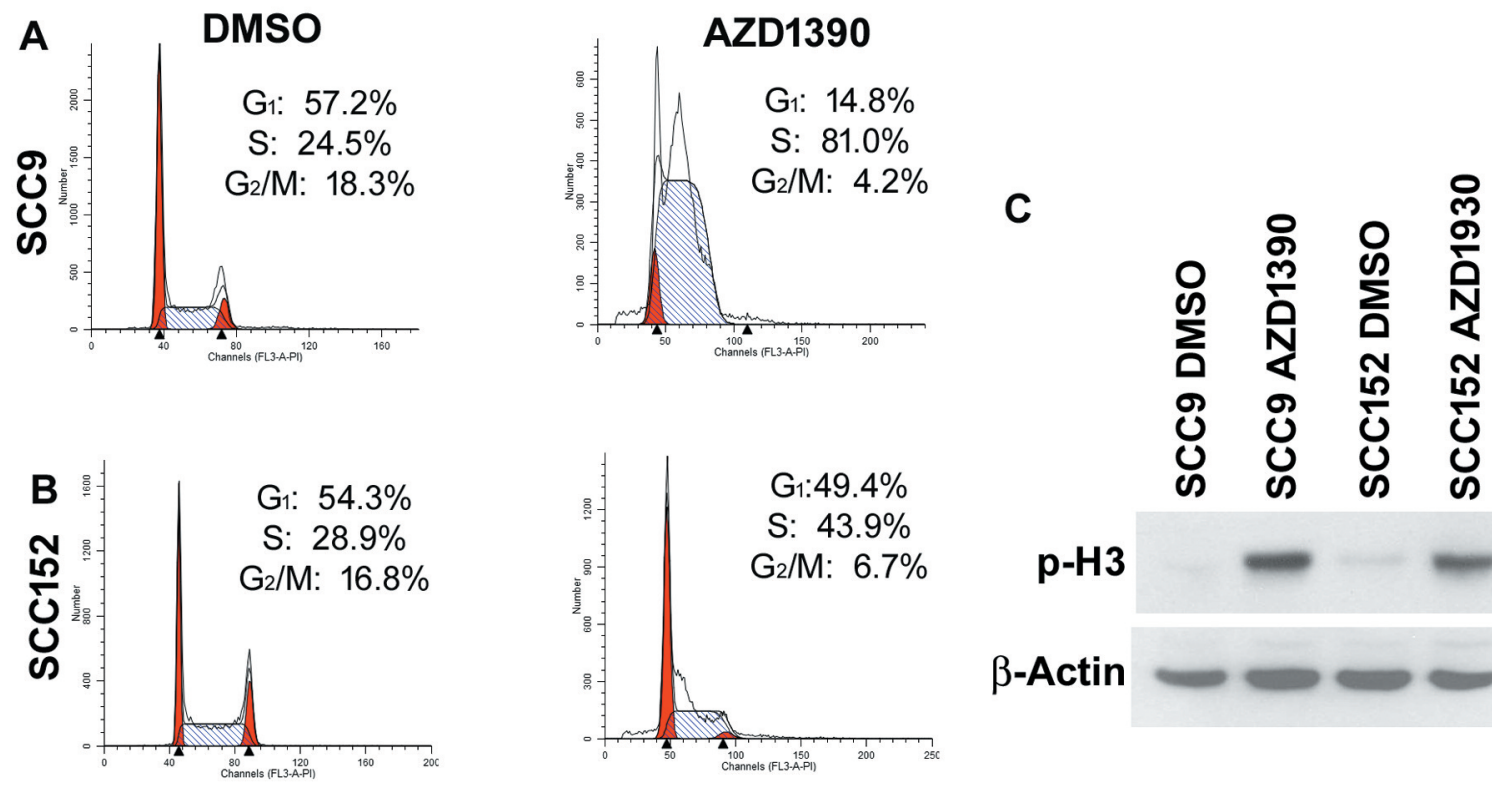

\section{p-H3}

$\beta$-Actin
$15 \mathrm{kDa}$

$42 \mathrm{kDa}$

Figure 4. Inhibition of ataxia telangiectasia mutated (ATM) blocks head and neck cancer (HNC) cell lines at $G_{2} / M$ phase of the cell cycle. Cell-cycle analysis of dimethyl sulfoxide (DMSO)-treated and AZD1390-treated SCC9 (A) and SCC152 (B) cells is shown by fluorescence activated cell sorting. C: Increased phospho-histone H3 expression in SCC9 and SCC152 cells treated with AZD1390 compared to DMSO-treated cultures is shown by western blot. $\beta$-Actin expression was used to control for protein loading in each lane. Experiments were performed three times with similar results.

HPV- SCC9

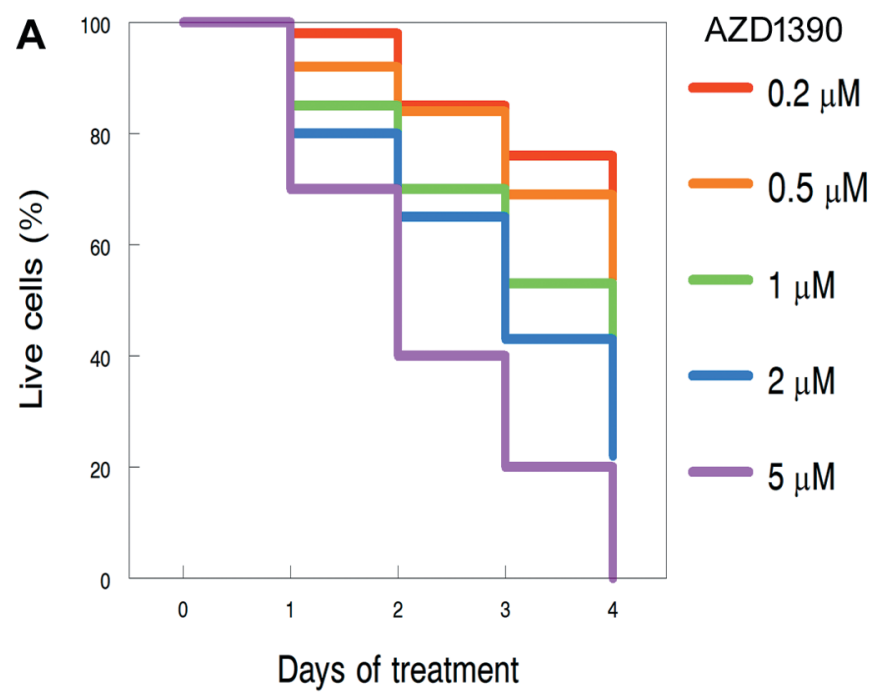

HPV+ SCC152

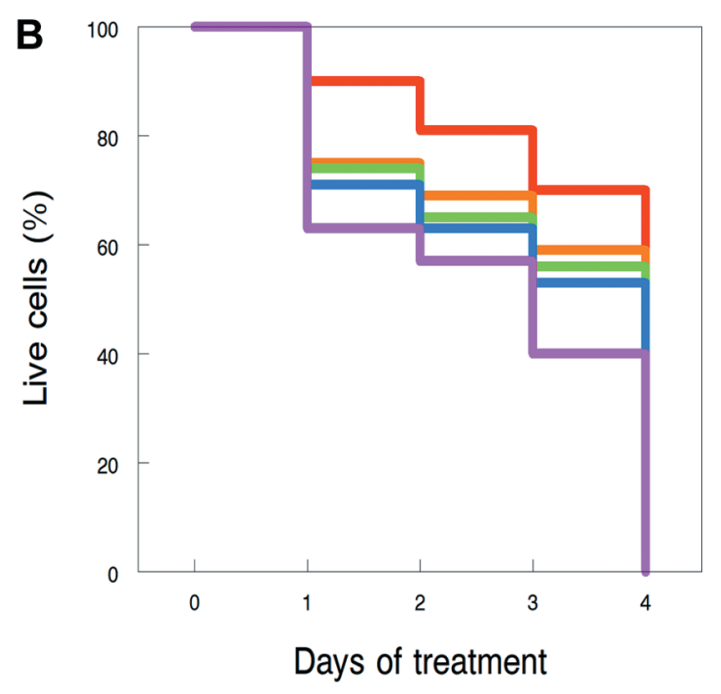

Figure 5. Ataxia telangiectasia mutated (ATM) inhibition induces death of head and neck cancer cell lines in vitro. Time course and dose response of SCC9 (A) and SCC152 (B) cell lines to AZD1390 is shown by trypan blue exclusion analysis. Experiments were performed three times with similar results.

AZD1390-treated mice due to extensive cell death (Figure 7E). The TUNEL ${ }^{+}$cell fraction was increased in AZD1390treated $\mathrm{HPV}^{-}$and $\mathrm{HPV}^{+}(21 \%$ vs. $0.3 \% ; p<0.006$; Figure $7 \mathrm{~F})$ tumors compared to vehicle-treated controls, although this is likely underestimated due to extensive nuclear fragmentation. These results indicate that AZD1390 treatment inhibits proliferation and induces cell death in transplanted $\mathrm{HPV}^{-}$and $\mathrm{HPV}^{+} \mathrm{HNC}^{\text {in vivo. }}$ 

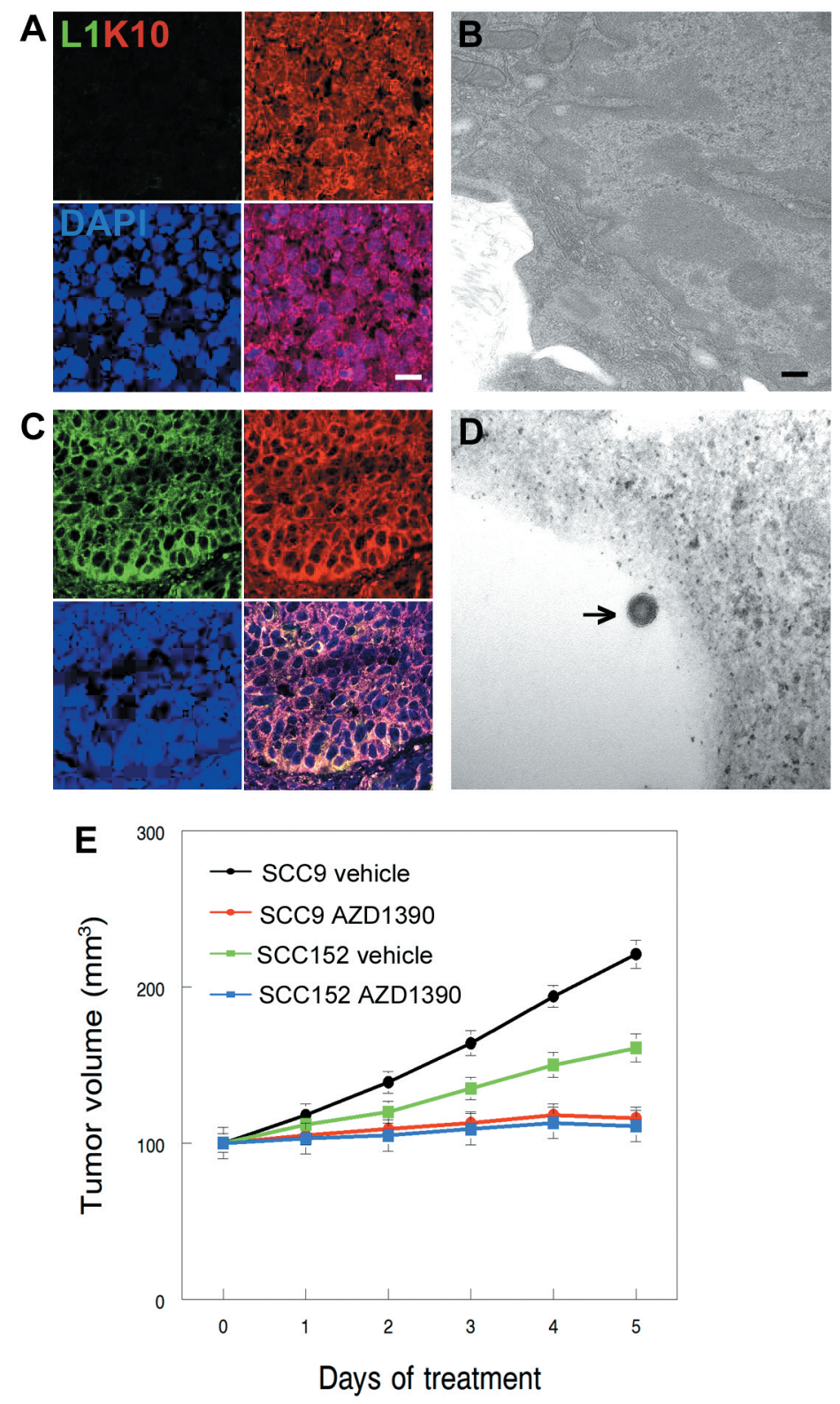

Figure 6. Head and neck cancer (HNC) xenografts produce human papillomavirus (HPV) virions. A: HPV L1 and keratin 10 (K10) expression is shown in an SCC9 xenograft under immunofluorescence microscopy. Nuclei were counterstained with 4',6-diamidino-2-phenylindole (DAPI). Scale bar $=10 \mu \mathrm{m}$. B: SCC9 xenograft is shown by transmission electron microscopy. Scale bar=50 nm. C: HPV L1 and K10 expression is shown in an SCC152 xenograft under immunofluorescence microscopy. D: HPV virion (arrow) in SCC152 xenograft as seen under transmission electron microscopy. E: ATM inhibition prevents growth of transplanted HNC cell lines in vivo. Tumor volume was measured in mice transplanted with SCC9 or SCC152 cells and treated with vehicle or AZD1390 for 5 days. Error bars indicate the standard error of the mean. Experiments were performed three times with similar results.

\section{Discussion}

Our data demonstrated that ATM co-localizes at $\mathrm{PCNA}^{+}$ DNA replication foci in both $\mathrm{HPV}^{-}$and $\mathrm{HPV}^{+}$human $\mathrm{SCC}$ lines. Previous study suggested that ATM activation at sites of DNA synthesis is the result of replication stress (11). ATM inhibition prevents double-strand DNA break repair in human SCC lines as indicated by increased 53BP1 foci. ATM has a well characterized role in repair of double-strand DNA breaks (12). ATM inhibition in human HNC lines prevents progression into $\mathrm{G}_{2} / \mathrm{M}$ phase with associated changes in cell cycle-regulatory protein expression. ATM also regulates the 


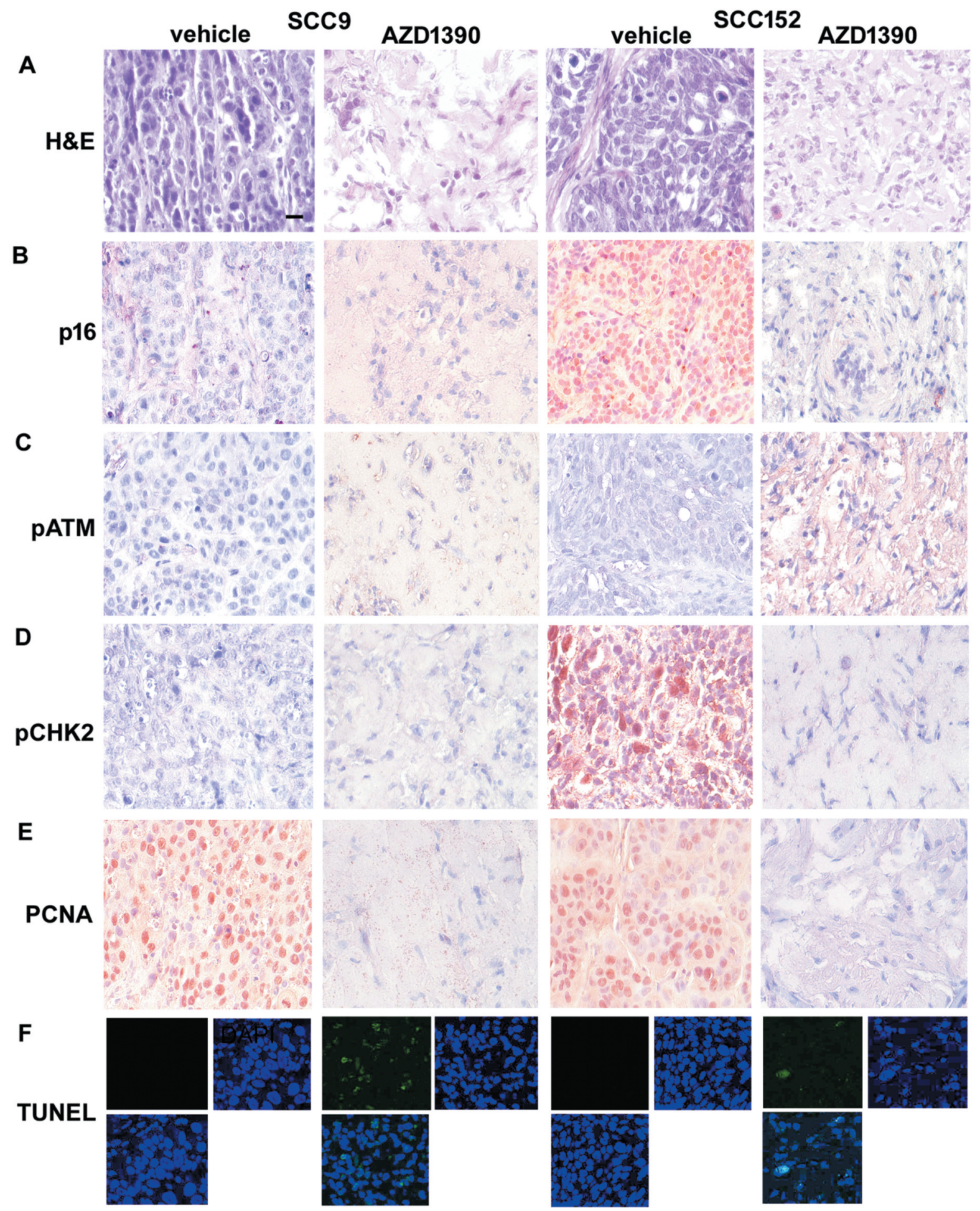

Figure 7. Inhibition of ataxia telangiectasia mutated (ATM) induces death of head and neck cancer cell lines in vivo. A: Histopathology of SCC9 and SCC152 transplanted tumors from vehicle-treated and AZD1390-treated mice as shown by hematoxylin and eosin staining. Immunohistochemical expression of cyclin-dependent kinase inhibitor $2 A$ (p16 INK4A) (B), phospho-(p)ATM (C), phospho-checkpoint kinase 2 (pCHK2) (D), and proliferating cell nuclear antigen (PCNA) (E) expression in SCC9 and SCC152 transplanted tumors from vehicle-treated and AZD1390-treated mice. Nuclei were counterstained with hematoxylin. F: Programmed cell death in SCC9 and SCC152 transplanted tumors from vehicle-treated and AZD1390-treated mice as shown by terminal transferase-mediated dUTP nick-end labeling (TUNEL) analysis. Nuclei were counterstained with 4',6-diamidino-2-phenylindole. Scale bar=10 $\mu \mathrm{m}$. Experiments were performed three times with similar results. 
DNA-damage checkpoint at this cell-cycle phase (13). In addition to ATM, CHK2 can be phosphorylated by other DNA damage kinases such as DNA-dependent protein kinase and polo-like kinase $3(14,15)$. Our data demonstrated that ATM inhibition has potent cell cycle-inhibitory effects which correlated with apoptosis in both $\mathrm{HPV}^{-}$and $\mathrm{HPV}^{+}$human SCC lines in vitro and in vivo. If double-strand DNA breaks are not repaired, cells may undergo programmed cell death to prevent replication of damaged DNA. DNA-damage induction is a common mechanism by which chemotherapeutic agents exert their anti-tumor effects.

Our data demonstrated that $\mathrm{p} 16^{\mathrm{INK} 4 \mathrm{~A}}$ is expressed by transplanted $\mathrm{HPV}^{+} \mathrm{SCC}$ lines in vivo. $\mathrm{p} 16^{\mathrm{INK} 4 \mathrm{~A}}$ is a diagnostic biomarker for $\mathrm{HPV}^{+}$oropharyngeal cancer, and was shown to inhibit homologous recombination-mediated DNA repair in $\mathrm{HPV}^{+}$oropharyngeal cancer cell lines (16).

HPV research has been impeded by the difficulty of producing virions in monolayer culture (17). Recombinant L1 protein assembles into virus-like shells in vitro (18), and HPV has been propagated in epidermal three-dimensional organotypic cultures $(19,20)$ and in epidermal transplants to the kidney capsule of severe combined immunodeficient mice (21). Our HPV virion model reported in this article has the advantage of technical simplicity and reproducibility using publicly available cell lines. Plasma HPV DNA was predictive of oropharyngeal cancer recurrence in a recent clinical study (22), although it was not clear whether the source of this DNA was tumor mediated virus production or cancer cell death.

Our study demonstrated that DNA double-strand break signaling is a target for therapy in both $\mathrm{HPV}^{+}$and $\mathrm{HPV}^{-}$ disease. $\mathrm{HPV}^{+} \mathrm{HNC}$ has better prognosis than $\mathrm{HPV}^{-}$tumors, which is likely due to their lower DNA mutational burden (23). Our study indicates that ATM inhibition is an effective therapy for both types of HNC, likely due to its cell cycleinhibitory effect which induces apoptosis. Future studies will determine infectivity of tumor-produced HPV and its possible role in HNC progression, and reconcile HPVinduced genetic changes with clinical prognosis.

\section{Conflicts of Interest}

The Authors declare no conflicts of interest.

\section{Authors' Contributions}

JW, KJG, and RDB performed experiments. CEP, AS, and DLC analyzed data and wrote the article.

\section{Acknowledgements}

The Authors thank Dr. Klara Valyi-Nagy (University of Illinois College of Medicine), Dr. Ke Ma, Figen Seiler, and Dr. Balaji Ganesh (University of Illinois Research Resources Center) for assistance with histopathology, confocal microscopy, electron microscopy, and flow cytometry. This study was supported by an award from the University of Illinois Center for Clinical and Translational Sciences and the University of Illinois Cancer Center.

\section{References}

1 Ferlay J, Colombet M, Soerjomataram I, Mathers C, Parkin DM, Piñeros M, Znaor A and Bray F: Estimating the global cancer incidence and mortality in 2018: GLOBOCAN sources and methods. Int J Cancer 144(8): 1941-1953, 2019. PMID: 30350310. DOI: $10.1002 /$ ijc.31937

2 Chow LQM: Head and neck cancer. N Engl J Med 382(1): 6072, 2020. PMID: 31893516. DOI: 10.1056/NEJMra1715715

3 Vermorken JB, Herbst RS, Leon X, Amellal N and Baselga J: Overview of the efficacy of cetuximab in recurrent and/or metastatic squamous cell carcinoma of the head and neck in patients who previously failed platinum-based therapies. Cancer 112(12): 27102719, 2008. PMID: 18481809. DOI: $10.1002 /$ cncr.23442

4 Leemans CR, Snijders PJF and Brakenhoff RH: The molecular landscape of head and neck cancer. Nat Rev Cancer 18(5): 269282, 2018. PMID: 29497144. DOI: 10.1038/nrc.2018.11

5 Cramer JD, Burtness B, Le QT and Ferris RL: The changing therapeutic landscape of head and neck cancer. Nat Rev Clin Oncol 16(11): 669-683, 2019. PMID: 31189965. DOI: 10.1038/s41571-019-0227-z

6 McKinnon PJ: ATM and ataxia telangiectasia. EMBO Rep 5(8): 772-776, 2004. PMID: 15289825. DOI: 10.1038/sj.embor.7400210

7 Durant ST, Zheng L, Wang Y, Chen K, Zhang L, Zhang T, Yang Z, Riches L, Trinidad AG, Fok JHL, Hunt T, Pike KG, Wilson J, Smith A, Colclough N, Reddy VP, Sykes A, Janefeldt A, Johnström P, Varnäs K, Takano A, Ling S, Orme J, Stott J, Roberts C, Barrett I, Jones G, Roudier M, Pierce A, Allen J, Kahn J, Sule A, Karlin J, Cronin A, Chapman M, Valerie K, Illingworth R and Pass M: The brain-penetrant clinical ATM inhibitor AZD1390 radiosensitizes and improves survival of preclinical brain tumor models. Sci Adv 4(6): eaat1719, 2018. PMID: 29938225. DOI: 10.1126/sciadv.aat1719

8 Percie du Sert N, Hurst V, Ahluwalia A, Alam S, Avey MT, Baker M, Browne WJ, Clark A, Cuthill IC, Dirnagl U, Emerson M, Garner P, Holgate ST, Howells DW, Karp NA, Lazic SE, Lidster K, MacCallum CJ, Macleod M, Pearl EJ, Petersen OH, Rawle F, Reynolds P, Rooney K, Sena ES, Silberberg SD, Steckler T and Würbel H: The ARRIVE guidelines 2.0: Updated guidelines for reporting animal research. Br J Pharmacol 177(16): 3617-3624, 2020. PMID: 32662519. DOI: 10.1111/bph.15193

9 Vassilev LT, Vu BT, Graves B, Carvajal D, Podlaski F, Filipovic Z, Kong N, Kammlott U, Lukacs C, Klein C, Fotouhi N and Liu EA: In vivo activation of the p53 pathway by small-molecule antagonists of MDM2. Science 303(5659): 844-848, 2004. PMID: 14704432. DOI: 10.1126/science. 1092472

10 Dhingra V, Verma J, Misra V, Srivastav S and Hasan F: Evaluation of Cyclin D1 expression in head and neck squamous cell carcinoma. J Clin Diagn Res 11(2): EC01-EC04, 2017. PMID: 28384866. DOI: 10.7860/JCDR/2017/21760.9329

11 Macheret $\mathrm{M}$ and Halazonetis TD: DNA replication stress as a hallmark of cancer. Annu Rev Pathol 10: 425-448, 2015. PMID: 25621662. DOI: 10.1146/annurev-pathol-012414-040424

12 Cho YJ and Liang P: S-phase-coupled apoptosis in tumor suppression. Cell Mol Life Sci 68(11): 1883-1896, 2011. PMID: 21437646. DOI: 10.1007/s00018-011-0666-x 
13 Cook JG: Replication licensing and the DNA damage checkpoint. Front Biosci (Landmark Ed) 14: 5013-5030, 2009. PMID: 19482602 . DOI: $10.2741 / 3584$

$14 \mathrm{Li} \mathrm{J}$ and Stern DF: Regulation of CHK2 by DNA-dependent protein kinase. J Biol Chem 280(12): 12041-12050, 2005. PMID: 15668230 . DOI: $10.1074 /$ jbc.M412445200

15 Bahassi el M, Robbins SB, Yin M, Boivin GP, Kuiper R, van Steeg H and Stambrook PJ: Mice with the CHEK2*1100delC SNP are predisposed to cancer with a strong gender bias. Proc Natl Acad Sci USA 106(40): 17111-17116, 2009. PMID: 19805189. DOI: 10.1073/pnas.0909237106

16 Dok R, Kalev P, Van Limbergen EJ, Asbagh LA, Vázquez I, Hauben E, Sablina A and Nuyts S: p16INK4a impairs homologous recombination-mediated DNA repair in human papillomavirus-positive head and neck tumors. Cancer Res 74(6): 1739-1751, 2014. PMID: 24473065. DOI: 10.1158/00085472.CAN-13-2479

17 Doorbar J: Model systems of human papillomavirus-associated disease. J Pathol 238(2): 166-179, 2016. PMID: 26456009. DOI: $10.1002 /$ path. 4656

18 Chen XS, Garcea RL, Goldberg I, Casini G and Harrison SC: Structure of small virus-like particles assembled from the L1 protein of human papillomavirus 16. Mol Cell 5(3): 557-567, 2000. PMID: 10882140. DOI: 10.1016/s1097-2765(00)80449-9

19 Dollard SC, Wilson JL, Demeter LM, Bonnez W, Reichman RC, Broker TR and Chow LT: Production of human papillomavirus and modulation of the infectious program in epithelial raft cultures. OFF. Genes Dev 6(7): 1131-1142, 1992. PMID: 1321068. DOI: $10.1101 / \operatorname{gad} \cdot 6.7 .1131$
20 Meyers C, Frattini MG, Hudson JB and Laimins LA: Biosynthesis of human papillomavirus from a continuous cell line upon epithelial differentiation. Science 257(5072): 971-973, 1992. PMID: 1323879. DOI: 10.1126/science.1323879

21 Bonnez W, DaRin C, Borkhuis C, de Mesy Jensen K, Reichman $\mathrm{RC}$ and Rose RC: Isolation and propagation of human papillomavirus type 16 in human xenografts implanted in the severe combined immunodeficiency mouse. J Virol 72(6): 5256-5261, 1998. PMID: 9573300. DOI: 10.1128/JVI.72.6.5256-5261.1998

22 Chera BS, Kumar S, Shen C, Amdur R, Dagan R, Green R, Goldman E, Weiss J, Grilley-Olson J, Patel S, Zanation A, Hackman T, Blumberg J, Patel S, Thorp B, Weissler M, Yarbrough W, Sheets N, Mendenhall W, Tan XM and Gupta GP: Plasma circulating tumor HPV DNA for the surveillance of cancer recurrence in HPV-associated oropharyngeal cancer. J Clin Oncol 38(10): 1050-1058, 2020. PMID: 32017652. DOI: 10.1200/JCO.19.02444

23 Seiwert TY, Zuo Z, Keck MK, Khattri A, Pedamallu CS, Stricker T, Brown C, Pugh TJ, Stojanov P, Cho J, Lawrence MS, Getz G, Brägelmann J, DeBoer R, Weichselbaum RR, Langerman A, Portugal L, Blair E, Stenson K, Lingen MW, Cohen EE, Vokes EE, White KP and Hammerman PS: Integrative and comparative genomic analysis of HPV-positive and HPV-negative head and neck squamous cell carcinomas. Clin Cancer Res 21(3): 632-641, 2015. PMID: 25056374. DOI: 10.1158/1078-0432.CCR-13-3310

Received August 13, 2021

Revised October 11, 2021

Accepted October 14, 2021 